\title{
Novas tecnologias, riscos e oportunidades na perspetiva das crianças
}

\author{
Ana Francisca Monteiroi \& António José Osórioii \\ Universidade do Minho, Portugal
}

\begin{abstract}
Resumo
Assumindo que as crianças são agentes sociais ativos que constroem as suas próprias culturas, esta pesquisa pretendeu compreender as suas perspetivas acerca do papel que as novas tecnologias, em particular a Internet, têm nas suas vidas. Tomou ainda como vertentes específicas os riscos, os desafios de segurança e as oportunidades que o uso de tecnologias digitais pode ou não representar, a partir do ponto de vista das crianças e da dimensão social do fenómeno tecnológico, ou seja, da forma como desenvolvimento tecnológico e práticas sociais se inter-relacionam e constroem mutuamente. Com base numa investigação etnográfica, são aqui retratadas as culturas 'digitais' que as crianças estão a construir e as reinterpretações que fazem dos conceitos de risco, segurança e oportunidade. Esta abordagem foca como este tipo de experiências são vividas quotidianamente, no contexto de estruturas socioculturais específicas.
\end{abstract}

Palavras-chave

Crianças; Novas tecnologias; Riscos; Oportunidades

\section{Introdução}

Compreender o que é ser criança, nas denominadas sociedades ocidentais da atualidade, requer um conhecimento profundo da sua relação com as novas tecnologias e da mediação tecnológica das experiências de socialização, lazer, comunicação e aprendizagem. Falar com amigos, ocupar 
os tempos livres e estudar são atividades que parecem depender cada vez mais do acesso a tecnologia. Seja enquanto ferramenta social ou educativa, a sua relevância está igualmente espelhada no investimento que as famílias direcionam para o acesso à Internet.

Esta interação entre crianças e tecnologias está ainda investida de grandes esperanças e receios. É fácil encontrar, sobretudo no tratamento que a comunicação social faz deste tema, uma celebração das oportunidades a ela associadas e uma dramatização dos perigos. São paradoxalmente populares a ideia de que estamos perante uma geração digital, líder na exploração das oportunidades que o digital encerra, e a previsão de que a infância está destinada a desaparecer, corrompida pelas informações agora ao alcance das crianças e comportamentos nelas provocados.

Este projeto surgiu neste contexto com dois propósitos centrais: i) numa perspetiva mais sociológica, compreender a relação entre crianças e novas tecnologias e os sentidos de que estas se revestem, na perspetiva das próprias crianças; ii) numa ótica educativa, contribuir para a promoção de um equilíbrio entre oportunidades e riscos das novas tecnologias que potencie as primeiras e reduza as consequências negativas dos segundos. Partindo do pressuposto de que as crianças são agentes sociais ativos que constroem as suas próprias culturas, esta abordagem privilegia os seus pontos de vista. Procura, assim, compreender estes fenómenos a partir dos significados e códigos socioculturais que as próprias crianças constroem.

Neste texto são apresentados os resultados finais deste trabalho. Com base numa abordagem etnográfica, ele realça como as crianças: desenvolvem sentidos de pertença e identidade através da apropriação de novas tecnologias; problematizam aspetos relativos à aceitação social e reputação; valorizam as questões de segurança a partir de reinterpretações específicas e encaram com ambiguidade conceitos como o de 'estranho' e 'vício'; não conceptualizam as suas práticas como oportunidade. Em conclusão, esta pesquisa destaca, por um lado, como as crianças criam os seus próprios mundos socioculturais e espaços de autonomia através das novas tecnologias; por outro, como as medidas destinadas a beneficiar ou proteger as crianças online se distanciam das suas próprias culturas, podendo tornar-se excessivamente prescritivas e estigmatizantes. Defende-se uma abordagem mais situada destas temáticas, capaz de valorizar as culturas das 
crianças e considerar as circunstâncias e contextos socioculturais em que as suas experiências digitais ocorrem e ganham sentido.

\section{Enquadramento}

Partindo do pressuposto de que as crianças são agentes sociais ativos que constroem as suas próprias culturas, este trabalho desenvolve-se em torno da conceção da infância como construção social e da criança como ator social (James, Jenks, \& Prout, 1998; James \& Prout, 1997; Jenks, 1992, 1996; Prout, 2005; Qvortrup, 1991). Trabalhadas no âmbito da designada Nova Sociologia da Infância, isto é, de um foco sociológico mais recente na análise da infância 'em si mesma' (Sarmento, 2008), estas noções vieram contrariar o primado da natureza na compreensão do que é ser criança e do que constitui a infância. Face a uma definição universal por referência a padrões de desenvolvimento biológico e psicológico, elas destacam a sua autonomia social e geracional, reconhecendo a agência social das crianças e a sua capacidade de construir expressões culturais próprias. Este enfoque discute o reconhecimento da infância como categoria social autónoma, que merece ser estudada por si própria e não a partir das perspetivas dos adultos (James \& Prout, 1997; Sarmento, 2004). Desta ótica, as crianças são cidadãos plenos, cujos direitos à participação e cidadania se colocam no presente, não apenas com vista à preparação do seu futuro (Tomás, 2007).

Mais recentemente, alguns autores têm vindo a apontar excessos a estas perspetivas, nomeadamente ao foco quase exclusivo da investigação sociológica sobre a agência das crianças (Prout, 2005, 2011; Tisdall \& Punch, 2012). A investigação é, por estes investigadores, chamada a reconsiderar a complexidade e ambiguidade da infância através de abordagens interdisciplinares, atentas às interações entre estrutura e agência, dimensões biológicas e psicológicas, entre outras dicotomias (Prout, 2005, 2011). Como escreve Prout (2005), "a infância não deveria ser entendida como natural nem cultural, mas como uma multiplicidade de 'naturezas-culturas', isto é, uma variedade de híbridos complexos, constituídos por materiais heterogéneos que emergem através do tempo" (p. 144). Realça-se aqui a necessidade de privilegiar a investigação interdisciplinar, capaz de reconhecer tanto o estatuto social das crianças como as suas especificidades biopsicossociais (Prout, 2005, 2010). 
No que diz respeito à relação que as crianças têm vindo a estabelecer com as novas tecnologias, a investigação mostra que estas são adotadas cada vez mais cedo, de forma intensa, motivada e autónoma, como práticas de comunicação, entretenimento, aprendizagem e outras. O apelo alargado pelo uso de redes sociais e jogos é bem conhecido e está evidenciada a interligação entre estas tendências, as questões de género, estatuto socioeconómico e condições de acesso e uso das tecnologias, nomeadamente na reprodução de desigualdades sociais (Almeida, Alves, \& Delicado, 2011; Livingstone, Haddon, \& Gorzig, 2012; Livingstone \& Haddon, 2009; Ponte, 2012).

Está também desmistificada a ideia de que há uma geração digital, naturalmente apta para tirar partido das tecnologias digitais ou indefesa perante os seus efeitos negativos (Buckingham, 2000). De uma forma geral, além de espelhar a diversidade de usos, os estudos indicam que muitas oportunidades estão apenas ao alcance de uma minoria e os riscos são menos alarmantes do que os discursos mais críticos deixam antever (Livingstone et al., 2012; Livingstone \& Haddon, 2009). A insuficiência epistemológica do paradigma dos efeitos dos media (Livingstone \& Hargrave, 2006; Livingstone, 1996, 1999) é, aliás, cada vez mais consensual. A imagem do consumidor passivo e acrítico que se limita a absorver a mensagem mediática é hoje considerada lacunar. Neste sentido, Lievrouw e Livingstone (2006) alertam para a necessidade de encarar o desenvolvimento tecnológico e as práticas sociais como processos que se constroem mutuamente. Nesta aceção, tanto o conceito de novas tecnologias, como o de oportunidade e risco, são resultado de processos recíprocos e contínuos de reconfiguração, sendo distinguidos, tendo em conta não só características tecnológicas, mas também os contextos sociais em que estão integradas e a forma como são adotadas.

Menos desenvolvido, sobretudo para o contexto português, está o conhecimento sobre como estas práticas ocorrem e são construídas no dia a dia das próprias crianças, no âmbito dos seus contextos socioculturais, significados e valores específicos. Mais do que conhecer os padrões de difusão e apropriação das novas tecnologias ou os impactos que estas possam exercer, trata-se de compreender a forma como são usadas no quotidiano pelas crianças e o papel que ocupam nas suas vidas, focando esta 
temática a partir da perspetiva das próprias crianças e jovens, das suas agendas e do modo como se apropriam das novas tecnologias, nos contextos em que o fazem. São referência nesta abordagem os trabalhos coordenados por David Buckingham (1993, 1996, 2000; Buckingham \& Bragg, 2004) e Sonia Livingstone (2002; Livingstone \& Bovill, 2001), no Reino Unido, e Danah Boyd (2007, 2008) e Mizuko Ito (2005, 2008; 2010), nos Estados Unidos da América. Em Portugal, este espaço de pesquisa tem vindo a ser explorado pelo projeto 'Crianças e Internet' (Almeida et al., 2011).

\section{Métodos e ética}

Esta pesquisa pretendeu compreender o papel que as novas tecnologias têm na vida das crianças na sua própria perspetiva, ou seja, do ponto de vista das suas preferências, motivações, valores e formas de estar e comunicar entre grupos de amigos/as. Centrou-se em particular na Internet e nas oportunidades ou riscos que esta pode representar, procurando entender como as crianças dela se apropriam e como encaram os seus desafios, positivos e negativos. Neste sentido, foi desenhada uma abordagem qualitativa de teor etnográfico, sustentada no que é designado na literatura como "investigação com crianças" (Christensen \& James, 2000a; Lobe, Simões, \& Zaman, 2009). Este posicionamento reflete o reconhecimento da infância como categoria social de estatuto próprio e das crianças como interlocutores indispensáveis e competentes na investigação e ação sobre as suas vidas e mundos sociais (Christensen \& James, 2000b). Trata-se, em suma, de uma abordagem que procura incluir as crianças no próprio desenho metodológico, de forma a adaptar e potenciar a capacidade de os métodos e técnicas implementados darem conta das suas culturas.

Especificamente, foram realizadas sessões de observação participante, entrevistas e propostas práticas para a criação de conteúdos multimédia (posters, vídeos, páginas do Facebook). Não obstante esta vertente, implementada com base na literatura que discute a capacidade de os métodos criativos permitirem que os utilizadores demonstrem nos seus próprios termos aquilo que fazem com as novas tecnologias (Buckingham, 2009; Gauntlett, 2007; Morrow, 2007), privilegiou-se a observação e o diálogo com as crianças. Foi efetivamente nas sessões menos estruturadas que os participantes mais facilmente expressaram a sua forma de estar e ver o 
mundo, bem como aceitaram a presença e participação da investigadora. Esta abordagem exigiu ainda uma avaliação detalhada do sentido ético da pesquisa e do papel da investigadora enquanto participante (Alderson \& Morrow, 2011). Considerando, por um lado, as singulares preocupações éticas que a pesquisa com crianças convoca e, por outro, a ética como prática contínua, e não apenas a observação de normas definidas a priori, importa um questionamento constante, destinado a considerar os dilemas e circunstâncias com que a investigação se depara à luz da dimensão ética (Alderson \& Morrow, 2011; Tisdall, Davis, \& Gallagher, 2009).

Participaram neste estudo 22 crianças, 14 raparigas e 8 rapazes, com idades compreendidas entre 9 e 14 anos. O trabalho de campo decorreu em dois centros de atividades de tempos livres (ATL), na casa de 7 participantes e em dois centros de inclusão digital do Programa 'Escolhas' (centros para a promoção do uso de novas tecnologias em zonas desfavorecidas), num total de 90 encontros. Com o estatuto de Instituições Particulares de Solidariedade Social (IPSS), os ATL situavam-se em zonas urbanas, nas imediações de escolas básicas, sendo frequentados pelos alunos no final das aulas. $O$ trabalho desenvolvido em residências decorreu numa segunda fase, com um dos grupos de participantes de um dos centros. Ambos os centros de inclusão digital se destinavam a crianças de famílias desfavorecidas, sinalizadas pelos projetos como em risco de exclusão, designadamente habitantes de periferias urbanas e membros de grupos étnicos.

Apenas algumas das crianças frequentadoras dos centros de inclusão digital não tinham acesso doméstico a tecnologias, não dispondo de computador próprio ou ligação à Internet. Para os restantes participantes, o acesso nas próprias casas estava sujeito a uma ou mais das seguintes limitações: restrições de tempo impostas pelos pais; partilha de dispositivos com os pais e/ou irmãos; ligações à Internet com capacidade limitada, em termos de velocidade e tempo. Ainda que numa escala menor, estas aplicavam-se também ao número reduzido de participantes que designava o computador portátil como sendo "próprio", por lhes ter sido oferecido como prenda de anos ou Natal.

Os dados foram submetidos a uma análise temática (Bogdan \& Biklen, 2003; Braun \& Clarke, 2006). À exceção das sessões de participação nas atividades habituais dos centros de inclusão digital, os encontros foram 
gravados e integralmente transcritos. Do conjunto de dados fizeram ainda parte notas de campo e memorandos. Através do software de análise qualitativa NVivo, estes dados foram selecionados e organizados em três grandes temas (contextos, usos/ objetivos, problemas), 13 subtemas $^{1}$ e 22 subcódigos $^{2}$. Por fim, os temas foram apresentados por escrito na tese de doutoramento que marcou o fim deste percurso, sob os títulos: Novas tecnologias no quotidiano das crianças; Sentidos do uso de tecnologias digitais; Problemas "online" (Monteiro, 2013). A escrita foi, assim, a fase em que a organização e a interpretação dos dados se materializou e finalizou (Richardson, 1994). Este trabalho assume, então, uma orientação construtivista, sendo entendido como um processo mutuamente construído pelo investigador, participantes, espaços e tempos de pesquisa, não obstante o papel central que o investigador, enquanto coprodutor, selecionador e intérprete dos dados, desempenha.

\section{Resultados}

\section{Identidade e sociabilidade}

Jogar, falar no Facebook, publicar e comentar fotos ou trocar mensagens de telemóvel estão entre as poucas formas de diversão, comunicação e convivência entre amigos/as que são exclusivas das crianças, ou seja, autónomas face ao mundo em que são os adultos que comandam. E são realmente poucos os espaços onde as crianças podem, atualmente, ter este tipo de autonomia, isto é, os espaços que são apenas deles, mundos dos quais os adultos não fazem parte e onde as crianças desenvolvem amizades e experiências de vida por si só. Neste sentido, as crianças utilizam as novas tecnologias para criar as suas próprias culturas, sendo estas atividades importantes para a integração nos grupos de amigos/as (Ito et al., 2010). Jogos, redes sociais e telemóveis são um fator central na integração entre pares, uma vez que quem não sabe ou não participa dificilmente acompanha as atividades em que os/as amigos/as estão envolvidos, os temas sobre os quais conversam, os/as novos/as amigos/as que conhecem, os problemas que têm, entre outros. Há exceções, mas se os/as amigos/as são fãs de um determinado jogo, usam o Facebook ou mensagens de telemóvel para "conversar" (expressão usada por um dos participantes do estudo para descrever a troca de comentários em fotos do Facebook) ou combinar 
atividades, manter-se à parte dessas interações dificulta a integração no grupo. O seguinte excerto exemplifica esta ideia:

Lollipop (rapariga, 14 anos): O teu Facebook? Como te chamas?

Movie (rapariga, 9 anos): Não tenho.

Lollipop: Não tens Facebook? Ó coitadinha!

Relativamente aos jogos, a motivação está relacionada com o desejo de competir, mas também de colaborar. Há vários aspetos que as crianças, em particular os rapazes, gostam nos jogos, como a sensação de conseguir ultrapassar um obstáculo, fazer a escolha acertada, explorar mundos de ficção ou simplesmente ter alguma coisa para fazer quando se está sozinho. No entanto, nenhum é tão valorizado como a competição. As crianças gostam de entrar em disputas e rivalizar pela posição do vencedor. Este é o que ganha, mas também o que sabe jogar, é bom estratega e lutador, ou seja, não desiste facilmente perante os obstáculos. Esta competitividade é, contudo, vivida num espírito de fair play e colaboração. Importa ganhar de forma justa e por mérito próprio, o que faz do jogo uma atividade intensamente partilhada. Jogar é acompanhado de conversas ou trocas de informações sobre estratégias, bem ou mal sucedidas, conquistas, pedidos de ajuda, risos, entre outros. Mesmo quem aparenta jogar sozinho está, muitas vezes, a conversar com amigos/as através do jogo ou de outra plataforma de comunicação online, ou faz disso motivo de conversa no dia de escola seguinte. Como descreve a Lol (rapariga, 12 anos), a propósito de alguns dos rapazes do seu grupo: "Eles passam a vida. Saem da sala [de aula] começam logo a falar dos jogos". Além da sua forte componente de entretenimento, os jogos são então uma atividade intensamente social, através da qual identidade, reputação e estatuto entre amigos/as se definem. O seguinte excerto, retirado da entrevista final com um dos grupos de rapazes, exemplifica esta ideia:

Investigadora: Ah, agora acho que vocês gostam dos jogos mesmo pela competição, quem é que joga melhor, quem fica à frente!

Xerife (rapaz, 12 anos): Eu é mesmo só para me distrair. De vez em quando. Investigadora: É? [Risos]. Eu ouvi-vos várias vezes dizer: "Ai eu tenho este monstro e tu não tens! Ai...".

Frize (rapaz, 12 anos): Não é Xerife?

Investigadora [rindo]: "Ai, vamos fazer uma corrida, vou ficar em primeiro!". Xerife: Eu ganhei. 
As raparigas gostam mais do Facebook, sobretudo da publicação de fotos e da troca de comentários sobre essas imagens. Esta partilha de fotos pessoais, individualmente ou em grupo, origina o que alguns participantes designaram de conversas, referindo-se à sucessiva troca de comentários. "Conversa-se" em particular sobre os atributos pessoais, físicos e de caráter $\mathrm{da}(\mathrm{s})$ pessoa (s) retratada(s), mas também se comenta os acontecimentos ou contextos que as imagens recordam. Assim, por exemplo, uma foto de um grupo de amigas numa viagem pode motivar comentários sobre a sua aparência ou traços de personalidade, mas também servir para voltar a rir por terem perdido o avião, lembrar o sabor do crepe que provaram ou como era linda a vista da Torre Eiffel. Nestas ou através destas conversas constroemse ou fortalecem-se amizades e (re)vivem-se experiências. Por outro lado, estas conversas fazem do Facebook um espaço onde se define a popularidade e estatuto de cada um dentro do grupo. Esta popularidade e estatuto estão associados à quantidade de comentários e aos elogios que recebem. Os rapazes também participam nestas interações, mas mais através da partilha de comentários do que da publicação de fotos. As seguintes afirmações realçam a importância dos comentários, em relação ao estatuto e à autoimagem:

Investigadora: Mas quando pedes para comentar [fotos], tipo, é porquê?

Raio (rapariga, 12 anos): Porque nunca comentou e queria saber o que é que ele acha.

Lol (rapariga, 12 anos): Eu gosto do Hi5 porque gosto de saber o que as pessoas pensam de mim.

Publicar fotos e trocar comentários no Facebook são, assim, formas de "conversar" e, à semelhança dos jogos, competir e colaborar.

As relações entre amigos/as estão, por outro lado, sujeitas a regras que se torna importante respeitar. Relativamente às redes sociais, importa: i) ter o perfil atualizado com fotos recentes, não necessariamente em grande número, mas que identifiquem a pessoa e partilhem vivências; ii) deixar e retribuir comentários positivos nas fotos dos/as amigos/as, reforçando assim a sua reputação; iii) agradecer os comentários feitos às próprias fotos, com vista ao reconhecimento mútuo. No caso dos jogos, interessa manter um nível 
competitivo e um espírito de fair playe colaboração. Entre os jogadores, pode mesmo ser mal visto partilhar e comentar fotos nas redes sociais, como nota o Xerife (rapaz, 12 anos): "É gozo. Ir para o Facebook comentar pessoas. Tenho mais que fazer!". As relações de amizade também se desenvolvem de acordo ou através destas regras, podendo, por exemplo, um comentário negativo despoletar uma zanga entre amigos ou o fim de uma amizade. Nas palavras da Raio (rapariga, 12 anos): "[Quando] eu peço pa[ra] comentar e não comentam nada de jeito (...) fico chateada!".

Respeitar os compromissos que se criam no contexto destas culturas 'digitais' exige, ainda, um uso intenso. No caso dos jogadores, porque é necessário treinar mas sobretudo, tendo em conta a forma como funcionam os jogos sociais ${ }^{3}$, jogar com regularidade. Nesta pesquisa foi observada, em particular, a competição em torno do jogo 'Monster Galaxy', ao qual um dos grupos de rapazes acedia através do Facebook. Este consistia, genericamente, em percorrer mundos e capturar monstros por meio de lutas. Os rapazes discutiam continuamente quem tinha maior quantidade ou os monstros mais raros, trocavam dicas de onde os encontrar e como os capturar, entusiasmavam-se perante os duelos mais difíceis e pesquisavam informações online, usando o Google, o YouTube ou sites especializados, para descobrir estratégias. Os jogadores ditos "mais viciados", ou seja, os que dedicavam mais tempo aos jogos, eram também os que se mostravam mais capazes de vencer as competições.

Para os fãs do Facebook, é importante estar constantemente em contacto, de forma a acompanhar e reagir em tempo útil às conversas do grupo. Se alguém publica e inicia uma conversa em torno de uma foto, tornase mais interessante e relevante comentar hoje do que fazê-lo amanhã, dois dias depois ou daqui a uma semana. Por outro lado, há amigos/as mais próximos/as ou mais interessantes de cujas conversas é importante fazer parte. Assim, interessa estar sempre em contacto, de modo a saber o que se passa com os/as amigos/as e participar nestes "encontros digitais" enquanto eles se mantêm atuais. O uso do telemóvel foi pouco explorado neste estudo, mas surgiu neste contexto para permitir um contacto permanente. Como descreve a Teclas (rapariga, 12 anos), "falar com os amigos" para saber as "novidades". A Raio (rapariga, 12 anos) usa o mesmo termo para descrever o uso que faz do Facebook: 
Investigadora: E no Facebook normalmente vês o quê?

Raio: As novidades que há.

As novas tecnologias suportam, então, o desenvolvimento de relações sociais de proximidade. Elas servem para conhecer novos/as amigos/as, algo que as crianças apreciam, estabelecendo redes de comunicação alargadas. O grupo de amigos/as não é de facto composto apenas por companheiros de turma ou escola, antes se estende a contactos em escolas vizinhas, amigos/as de amigos/as ou familiares distantes. Geografias mais distantes também se conectam a partir de interesses comuns neste estudo, com destaque para o gosto pelos jogos. Os jogadores competem, colaboram e trocam informações com jogadores de diferentes países e continentes. Contudo, é no contexto das relações sociais de proximidade, nomeadamente as que se criam com os colegas da própria escola, com quem se convive presencialmente e com regularidade, que a utilização de novas tecnologias se torna mais intensa. Efetivamente, é com estes que se realizam e partilham as jogadas mais emocionantes, as conversas e os "encontros digitais" descritos. Neste sentido, os laços sociais definem-se, fortalecem-se e enfraquecem-se a partir de interações mediadas pelas novas tecnologias, designadamente comentários em fotos ou competição nos jogos.

Cabe também referir, como se vai percebendo pelas práticas atrás descritas, a forte inter-relação que se estabelece entre "real" e "virtual". As amizades, os sentimentos entre amigos/as e mesmo os acontecimentos são continuamente (re)vividos e (re)construídos, ora presencialmente, ora através das tecnologias. "Real" e "virtual", "offline" e "online" são dimensões conexas, que se reproduzem e influenciam mutuamente. É neste sentido que, neste artigo, se utilizam termos relativos ao espaço virtual frequentemente entre aspas, uma vez que, na maior parte das interações observadas, online e offline surgem sobrepostos. As conversas, amizades, querelas ou atividades, nomeadamente jogar, que começam online, continuam ou têm reflexos offline. O seguinte excerto expressa estas ligações:

SirX (rapaz, 13 anos): Por exemplo, eu uma vez, numa atividade [de escuteiros], conheci uma rapariga que não a conhecia de lado nenhum. Só depois é que percebi quem era, já tinha falado mais com ela e assim.

Investigadora: Ahhh, percebeste quem era de ter falado no Facebook? Ou teres visto o perfil? 
SirX: No Facebook não foi tanto, foi mais na... realidade, se é assim que se pode chamar.

Mesmo sendo muito importante, este tipo de vivências não é, contudo, conceptualizado pelas crianças como uma oportunidade. Oportunidade acabou por se destacar, nesta pesquisa, como um conceito vazio. Por um lado, porque surge sempre a par do conceito de risco, o qual se sobrepõe, gerando reações imediatas e dominando os discursos. Por outro lado, as crianças não o usam espontaneamente. Neste sentido, oportunidade pode ser considerado um conceito próprio dos adultos, associado à ideia de que a infância é um estádio de desenvolvimento, uma fase quase exclusivamente dedicada à aprendizagem. Assim, o conceito de oportunidade refere-se a benefícios educativos, o que contrasta com as dimensões que as próprias crianças valorizam, nomeadamente entretenimento, divertimento e identidade. Buckingham $(2000,2007,2008)$ descreve este contraste e destaca como os direitos das crianças incluem estas vertentes. São efetivamente estes direitos que as próprias crianças acentuam, ao encarar as tecnologias como os espaços sociais em que vivem e constroem as suas próprias identidades.

\section{Problemas online}

Neste estudo foram definidas três áreas de problemas: identidade e sociabilidade; risco e segurança; condições de acesso e uso das novas tecnologias. Destes, são os relacionados com identidade e pertença social que mais preocupam as crianças. Tal como descrito, jogar, estar no Facebook e trocar mensagens de telemóvel são atividades através das quais as crianças criam as suas próprias culturas, formas de estar, conviver e de se relacionar entre amigos/as. Como tal, há uma preocupação relativamente à possibilidade ou capacidade para participar nesses contextos, bem como corresponder às expectativas que neles se estabelecem. Trata-se, em concreto, de ser capaz de competir nos jogos, participar nas conversas que se desenrolam no Facebook, estar a par das "novidades" que se partilham através do telemóvel e conhecer e respeitar as regras estabelecidas. Uma participação efetiva nestas culturas exige um acesso regular, podendo a dificuldade para acompanhar os/as amigos/as originar problemas de integração. 
Existem, por outro lado, expectativas sociais especificamente definidas em relação à idade/maturidade, género e competência. Os participantes desta pesquisa concordam com a perceção geral de que as raparigas gostam mais das redes sociais e os rapazes dos jogos (Almeida et al., 2011). Esta divisão não é estanque mas é considerada típica, alargando-se ainda à forma como feminino e masculino são associados a apropriações, respetivamente, mais emotivas e técnicas (Almeida, Carvalho, Delicado, \& Alves, 2012). A dedicação que, nesta pesquisa, as raparigas revelaram a gerir os seus perfis nas redes sociais e os rapazes a jogar, sendo as opções dos mais velhos distintas das dos mais novos, espelham esta performance identitária. Competência refere-se, no contexto dos jogos, à capacidade de competir e, no caso da participação em redes sociais, à reputação ou popularidade. Os seguintes excertos retratam estas generalizações:

Tip (rapaz, 13 anos): Eles [rapazes mais novos] jogam muito os jogos do Facebook. Eu não vou para o Facebook para jogar.

Raio (rapariga, 12 anos): Eles [rapazes] [tanto] estão a jogar como estão nas redes sociais. Mas estão mais tempo a jogar do que... É, por exemplo, eu tenho que falar com um rapaz, ele diz: escreve um texto grande que depois vou jogar.

(...) As amigas [pedem para comentar]. Os rapazes não.

Astérix (rapaz, 12 anos): Não consigo passar este nível. Frize (rapaz, 12 anos): Ei Astérix! Que fraco. Uhhh!

Astérix: Não tenho culpa de ter as mãos mais pequenas.

Frize: Astérix, desculpa lá, és um fraco.

Astérix: Não tenho culpa de teres mais idade do que eu.

Lol (rapariga, 12 anos): Eu só tenho 200 e tal [comentários]. Há pessoas que têm 1000 e tal. E eu fico: dah! (...) Também sou a que tem há menos tempo. Tenho pa[ra] aí há um ano. Os outros já têm pa[ra] aí há cinco.

No contexto da família e dos centros educativos, as expectativas dizem respeito às questões de aprendizagem, saúde e segurança. Neste sentido, os participantes procuraram distanciar-se do que pode ser considerado como uma representação patológica do viciado na Internet. A maior parte assegurou utilizar pouco o computador e em particular para fins educativos, preferindo 
passar as horas de lazer na companhia de amigos. Negaram ainda entrar em contacto com estranhos. Um dos participantes equiparou também vício a sexting, prática com fortes conotações negativas. Um viciado foi descrito como alguém que faz um uso excessivo da Internet, descurando o trabalho escolar, a convivência com os amigos e até a alimentação. Mas mesmo os utilizadores mais frequentes, apelidados de viciados pelos colegas, negaram sê-lo. A Teclas (rapariga, 12 anos) faz mesmo uma associação direta entre os jogos de Facebook e benefícios pedagógicos:

Teclas: Estou muito habituada a jogar jogos, porque eu também gosto e passo, também tenho consola, tenho Nintendo, tenho PSP, e eu como sou um bocado viciada em jogos didáticos e isso... É fácil, para mim, depende, quem nunca experimentou e que não gosta muito!

Investigadora: Claro.

Teclas: É um bocado difícil.

Investigadora: Mas, [es]tavas a falar de jogos didáticos, que jogos?

Teclas: Ah, o Farmville, Petville, também gosto do Buzz.

Torna-se assim bastante difícil encontrar uma sintonia entre as esferas dos/as amigos/as e da família, isto é, as expectativas que em ambos se estabelecem relativamente ao uso de tecnologias digitais. Se a primeira valoriza uma presença 'online' frequente e participação bastante ativa em jogos e redes sociais, a segunda enaltece o distanciamento e reduz a validade dos usos à dimensão educacional, na sua vertente mais formal. Esta diz respeito à pesquisa de informação para trabalhos, nomeadamente criação de apresentações em Powerpoint e relatórios sobre temas específicos. No entanto, o equilíbrio entre estas perspetivas é algo que as crianças estimam, negando o que numa e noutra esfera é considerado desviante, apesar das óbvias contradições. Discurso e prática diferem, sendo a performance ou teatralização de identidades (Buckingham, 2008) a principal estratégia de superação. Num esforço para encontrar uma harmonia entre o que a família e os pares valorizam, comportamentos e posturas são redefinidos consoante o desempenho exigido em cada contexto. A Raio exemplifica esta tensão:

Raio (rapariga, 12 anos): A teoria dos meus pais e da minha irmã é mais tipo: "Ah, na nossa altura não havia computadores e não fazíamos nada disso. E tu tens treze anos, passas a vida no computador, que é isso?, não sei quê (...)". 
Mas eu não era por estar no computador, é porque não me apetecia mesmo (...). Agora digo que vou ao PC, [peço para ir] pa[ra] me controlarem, pa[ra] verem que não [es]tou assim tanto tempo.

No âmbito destas práticas e da tensão entre amigos/as e famílias, há vários conceitos que se tornam ambíguos. Numa dimensão cultural, vício remete para as preferências pessoais que distinguem cada um. É frequente ouvir as crianças dizer que estão viciadas em determinado jogo, série, entre outros, sem que isso se refira a um estado patológico. Como nota a Bolhas (rapariga, 12 anos): "Houve uma altura em que fiquei viciada nuns quantos de jogos. Mas mesmo viciada (...) Quando tinha que parar, parava, mas gostava muito de jogar isto". Por seu lado, o conceito de estranho exclui os contactos estabelecidos com outros jogadores dos jogos sociais, bem como os 'amigos/as de amigos/as'. Assim, este termo nem sempre acompanha uma perceção de risco. Os seguintes excertos expressam estas múltiplas significações, que se estendem a conceitos como o de amigo e falar: "Não é meu amigo, meu amigo daqui [do jogo]" (Teclas, rapariga, 12 anos); "Há pessoas que aceitam todos no Hi5, todos os pedidos de amizade. Eu não, só aceito os que conheço. Os da escola, os que conheço de vista, aceito" (Lol, rapariga, 12 anos); "Mas eu só lhe peço algumas coisas, de resto. Eu só lhe peço coisas para o jogo. Não falo com ele, que ele é inglês" (Xerife, rapaz, 12 anos). Por fim, o conceito de dados pessoais diz mais respeito a nome ou morada do que às partilhas sobre a vida pessoal, feitas através dos perfis de redes sociais.

Tendo em conta esta ambiguidade e, mais uma vez, as tensões entre as esferas da família e amigos/os, falar de risco na Internet remete para cenários muito específicos. Em particular, os casos de raparigas que conversam online e aceitam encontrar-se pessoalmente com homens mais velhos, a possibilidade de ser identificado nas redes sociais e perseguido por alguém ou o acesso a imagens de teor sexual. Neste sentido, para estar em segurança, basta não aceitar a amizade de pessoas desconhecidas, divulgar dados pessoais ou aceder a sites de pornografia. Tendo em conta a ambiguidade de conceitos como o de estranho e dados pessoais, estas noções preconcebidas dificilmente abarcam as especificidades e circunstâncias que caracterizam o quotidiano das crianças. Um caso contado pela Raio (rapariga, 12 anos) exemplifica estas limitações. Após aceitar a 
proposta de conhecer pessoalmente o primo de uma amiga, com quem tinha falado e trocado mensagens, a Raio veio a descobrir que se tratava de uma pessoa falsa, criada por essa mesma amiga. Apesar de estar efetivamente a falar com um estranho, a Raio não identificou essa experiência como tal, nem considerou estar a correr algum risco. Este sobressai, assim, como conceito estereotipado. No entender da Bolhas (rapariga, 12 anos), é, ainda, aborrecido: "Também o que é que vamos falar dos riscos? (...) Não é um tema muito interessante. (...) Até há palestras sobre isso". Esta noção de risco é ainda impermeável à forma como os jogos ditos violentos, as histórias assustadoras e, para os rapazes, as imagens de teor sexual são considerados elementos ou práticas culturais.

Face a esta noção estereotipada, os participantes deste estudo consideraram que só se envolve em situações de risco quem quer e está disposto a sofrer as consequências, sendo estas do conhecimento comum. Desta forma, fazem recair sobre si próprios o dever de o evitar, transformando-o numa questão de vontade moral. Ainda que possa promover um educativo sentido de responsabilidade, esta avaliação moral conduz a uma cultura de culpabilização e excesso de autocrítica, porventura bloqueadora do acesso a medidas ou redes de apoio. A Teclas (rapariga, 12 anos) sintetiza esta ideia de autorresponsabilização:

Investigadora: Há assim alguma coisa relacionado com a Internet que te preocupe ou...

Teclas: Só se aceitar pessoas que não conheça e começarem a falar para mim.

No que diz respeito ao risco, este trabalho vem então realçar o reduzido alcance e até efeito contraproducente de algumas estratégias de sensibilização, quando confrontadas com o quotidiano das crianças. Perante uma noção de risco restrita, alarmista e estigmatizante, perde terreno uma disponibilidade para pedir ajuda ou uma atitude de vigilância e aprendizagem. Tendo em conta estes resultados, este estudo realça como as medidas destinadas a beneficiar ou proteger as crianças online podem ser excessivamente prescritivas e estigmatizantes. Ao desconsiderar as suas perspetivas e os significados que a utilização de novas tecnologias tem nos seus quotidianos, exigem respostas que podem tornar-se incompatíveis com as suas próprias culturas e as exigências que enfrentam no âmbito dos grupos 
de amigos/as. A forma como risco e segurança assumem interpretações ambíguas, consoante o prisma a partir do qual são considerados, e oportunidade, como conceito vazio, reflete este antagonismo. Este trabalho defende, assim, uma abordagem mais situada e concreta destas temáticas, capaz de ter em conta as circunstâncias e contextos socioculturais em que as experiências 'digitais' das crianças ocorrem, bem como a identidade, expectativas e limites de cada criança. Falando de um conselho de segurança segundo o qual as crianças devem substituir as fotos pessoais por imagens de celebridades, animais, ou outros, a Lol (rapariga, 12 anos) sumariza as contradições que se criam entre a cultura das crianças e a forma como os adultos nela intervêm ou procuram intervir:

Lol: Imagine que eu tiro [tenho no Hi5] uma imagem de uma cantora. Se estiver lá a dizer "Esta cantora é muito não sei quê", a mim não me interessa nada. Eu quero lá saber. Tem é de ser de mim. Com imagens e frases que dizem sobre mim. Para isso fica no Hi5 deles!

\section{Conclusão}

Num contexto em que se mantém a preocupação e a insegurança relativamente aos benefícios e riscos que as novas tecnologias podem trazer às crianças e em que aumentam as iniciativas de investigação (Livingstone et al., 2012) e sensibilização, este estudo distingue-se por destacar a perspetiva das próprias crianças. O seu contributo é o de reconhecer e respeitar o seu ponto de vista, as suas culturas, expectativas e compromissos, contribuindo para que essa perspetiva possa ser integrada na forma como lidamos com estas questões. Com a convicção de que é necessário compreender as crianças para pôr em prática um acompanhamento adequado, ele realça e exemplifica o que pode resultar de as ouvir, estar familiarizado com as suas culturas e considerar com empatia as suas experiências quotidianas. Em suma, trata-se de incluir as crianças na forma como encaramos e procuramos potenciar os benefícios e minimizar os riscos da era digital.

As crianças criam efetivamente os seus próprios mundos, fazendo-o cada vez mais a partir do modo como usam as novas tecnologias. Compreender estas dimensões, avaliando os usos de tecnologias face aos contextos em que ganham sentido, potencia um conjunto de aspetos positivos: respeito pelos direitos das crianças, nomeadamente à identidade $\mathrm{e}$ 
lazer; compreensão mútua e aproximação entre distintas gerações, designadamente pais e filhos; promoção de medidas de benefício e segurança adequadas às culturas infantis e perspetivas das crianças sobre oportunidade e risco, à partida mais eficazes. Desta ótica, oportunidade e risco não são conceitos dicotómicos, antes assumem múltiplos significados, de acordo com diferentes costumes, valores e circunstâncias. Por fim, esta posição passa por ter em conta como as próprias crianças avaliam a positividade ou negatividade de determinadas práticas, necessitam efetivamente de acompanhamento ou estão dispostas a recebê-lo.

Estar atento e disponível para reconhecer a perspetiva das crianças e as experiências e problemas quotidianos não equivale, contudo, a saber como atuar. É este o principal desafio que se coloca para dar continuidade a este trabalho: saber como incluir as crianças nas decisões que tomamos relativamente aos seus ambientes digitais. Trata-se, de forma resumida, de considerar como podem as crianças participar efetivamente nas decisões que afetam as suas vidas, nomeadamente no que diz respeito ao uso de novas tecnologias e às oportunidades ou riscos que estas poderão potenciar. Só assim o interesse e a disponibilidade para compreender as suas perspetivas poderão ter reflexos práticos.

\section{Financiamento}

Este projeto foi financiado pela Fundação para a Ciência e Tecnologia, através de uma bolsa individual de doutoramento (SFRH / BD / 36262 / 2007).

\section{Notas}

1 Contexto - escolar, doméstico, público; Usos/ Objetivos - socializar, jogar, lazer, trabalhar, aceder a informação, aprender, criar; Problemas - identidade e sociabilidade, risco e segurança, condições de acesso e uso.

2 Risco e segurança - conteúdos sexuais, credibilidade, conteúdos violentos, direitos de autor e pirataria, comércio, contactos com estranhos, vício, dados pessoais, sexting, (cyber)bullying; Condições de acesso e uso - desigualdades, problemas técnicos, privacidade, competências, usabilidade; Vários - conhecer novos(as) usos ou ferramentas, personalizar, vantagens profissionais, virtual versus real, participar, partilhar informação, multitarefa. 
3 Para mais informações sobre jogos sociais ver Zagalo (2012), Comunicação e design dos jogos sociais, disponível em: https://dl.dropboxusercontent.com/u/ 3081588/papers/JogosSociais_2012_NZ.pdf.

\section{Referências}

Alderson, P., \& Morrow, V. (2011). The ethics of research with children and young people: A practical handbook. London: Sage.

Almeida, A. N., Alves, N. A., \& Delicado, A. (2011). As crianças e a Internet em Portugal: Perfis de uso. Sociologia, Problemas e Práticas, 65, 9-30.

Almeida, A. N., Carvalho, D., Delicado, A., \& Alves, N. A. (2012). Pela mão das crianças: Metodologias em construção. Atas do VII Congresso Português de Sociologia: Sociedade, Crise e Reconfigurações. Porto: APS.

Bogdan, R., \& Biklen, S. (2003). Investigação qualitativa em educação: Uma introdução à teoria e aos métodos. Porto: Porto Editora.

Boyd, D. (2007). Why youth (love) social network sites: The role of networked publics in teenage social life. In D. Buckingham (Ed.), Youth, identity, and digital media (pp. 119-142). Cambridge: MIT Press.

Boyd, D. (2008). Taken out of context: American teen sociality in networked publics. (Tese de doutoramento). University of California-Berkeley.

Buckingham, D. (1993). Reading audiences: Young people and the media. Manchester: Manchester University Press.

Buckingham, D. (1996). Moving images: Understanding children's emotional responses to television. Manchester: Manchester University Press.

Braun, V., \& Clarke, V. (2006). Using thematic analysis in psychology. Qualitative Research in Psychology, 3(2), 77-101.

Buckingham, D. (2000). After the death of childhood: Growing up in the age of electronic media. Cambridge: Polity Press.

Buckingham, D. (2007). The impact of the media on children and young people with a particular focus on computer games and the Internet. London: Centre for the Study of Children, Youth and Media.

Buckingham, D. (2008). Introducing identity. In D. Buckingham (Ed.), Youth, identity, and digital media (pp. 1-22). Cambridge: The MIT Press.

Buckingham, D. (2009). Creative' visual methods in media research: Possibilities, problems and proposals. Media, Culture \& Society, 31, 633-652.

Buckingham, D., \& Bragg, S. (2004). Young people, sex and the media: The facts of life? New York: Palgrave Macmillan.

Christensen, P., \& James, A. (2000a). Research with children: Perspectives and practices. London: Falmer Press.

Christensen, P., \& James, A. (2000b). Childhood, diversity and commonality: Some methodological insights. In P. C. \& A. James (Ed.), Research with children: Perspectives and practices (pp. 160-179). London: Palmer Press. 
Gauntlett, D. (2007). Creative explorations: New approaches to identities and audiences. Oxford: Routledge.

Ito, M., Baumer, S., Bittanti, M., Boyd, D., Cody, R., Herr-Stephenson, B., Horst, H. A., et al. (2010). Hanging out, messing around, and geeking out: Kids living and learning with new media. Cambridge, London: The MIT Press.

Ito, M., Horst, H., Bittanti, M., Boyd, D., Lange, B. H.-S. P. G., Pascoe, C. J., \& Robinson, L. (2008). Living and learning with new media: Summary of findings from the Digital Youth Project. Chicago: The John D. and Catherine T. MacArthur Foundation.

Ito, M., Okabe, D., \& Matsuda, M. (2005). Personal, portable, pedestrian: Mobile phones in japanese life. Cambridge: MIT Press.

James, A., \& Prout, A. (1997). Constructing and reconstructing childhood: Contemporary issues in the sociological study of childhood. London: The Falmer Press.

James, A., Jenks, C., \& Prout, A. (1998). Theorizing childhood. Cambridge: Polity Press.

Jenks, C. (1992). Introduction: Constituting the child. In C. Jenks (Ed.), The sociology of childhood. Essential readings (pp. 9-27). Hampshire: Gregg Revivals.

Jenks, C. (1996). Childhood. London: Routledge.

Lievrouw, L. A., \& Livingstone, S. (2006). Handbook of new media: Social shaping and social consequences. London: Sage.

Livingstone, S. (1996). On the continuing problems of media effects research. In J. Curran \& M. Gurevitch (Eds.), Mass media and society (pp. 305-324). London: Edward Arnold.

Livingstone, S. (1999). Social perspectives: Have the media ruined childhood? Interactions, 6(6), 36-41.

Livingstone, S. (2002). Young people and new media: Childhood and changing media environment. London: Sage.

Livingstone, S., \& Bovill, M. (2001). Children and their changing media environment: A european comparative study. New Jersey: Lawrence Erlbaum.

Livingstone, S., \& Haddon, L. (2009). Kids online: Opportunities and risks for children. Bristol: The Policy Press.

Livingstone, S., \& Hargrave, A. M. (2006). Harmful to children? Drawing conclusions from empirical research on media effects. In U. Carlsson (Ed.), Regulation, awareness, empowerment: Young people and harmful media content in the digital age (pp. 21-48). Gothenburg: Nordicom.

Livingstone, S., Haddon, L., \& Gorzig, A. (2012). Children, risk and safety online: Research and policy challenges in comparative perspective. Bristol: The Policy Press.

Lobe, B., Simões, J. A., \& Zaman, B. (2009). Research with children. In S. Livingstone \& L. Haddon (Eds.), Kids online: Opportunities and risks for children. Bristol: The Policy Press.

Monteiro, A. F. (2013). "Tem é de ser de mim": Novas tecnologias, riscos e oportunidades na perspetiva das crianças (Tese de doutoramento). Braga. Universidade do Minho. 
Morrow, V. (2007). Studying children's everyday worlds: Qualitative and creative methods. In K. Engwall \& I. Söderlind (Eds.), Children's work in everyday life. Stockholm: Institute for Futures Studies.

Ponte, C. (2012). Acesso, usos e competências. Resultados nacionais do inquérito EU Kids Online. In C. Ponte, A. Jorge, J. A. Simões \& D. S. Cardoso (Orgs.), Crianças e internet em Portugal: Acessos, usos, riscos, mediações: Resultados do inquérito europeu EU Kids Online. Coimbra: Minerva Coimbra.

Prout, A. (2005). The future of childhood: Towards the interdisciplinary study of children. London: Routledge.

Prout, A. (2010). Reconsiderando a nova sociologia da infância. Cadernos de pesquisa, 40(141), 729-750.

Prout, A. (2011). Taking a step away from modernity: Reconsidering the new sociology of childhood. Childhood: A Global Journal of Child Research, 1(1), 4-14.

Qvortrup, J. (1991). Childhood as a social phenomenon: An introduction to a series of national reports. Vienna: European Centre for Social Welfare Policy and Research.

Richardson, L. (1994). Writing: A method of inquiry. In N. K. Denzin \& Y. S. Lincoln (Eds.), Handbook of qualitative research (pp. 516-529). Thousand Oaks: Sage.

Sarmento, M. J. (2004). As culturas da infância nas encruzilhadas da 2a modernidade. In M. J. Sarmento \& A. B. Cerisara (Eds.), Crianças e miúdos: Perspectivas sócio-pedagógicas da infância e educação (pp. 9-34). Porto: Asa.

Sarmento, M. J. (2008). Sociologia da infância: Correntes e confluências. In M. Sarmento \& M. C. S. de Gouvea (Eds.), Estudos da infância (pp. 17-39). Petrópolis: Rio de Janeiro.

Tisdall, E. K. M., \& Punch, S. (2012). Not so "new"? Looking critically at childhood studies. Children's Geographies, 10(3), 37-41.

Tisdall, E. K. M., Davis, J., \& Gallagher, M. (2009). Researching with children and young people: Research design, methods and analysis. London: Sage.

Tomás, C. (2007). Paradigmas, imagens e concepções da infância em sociedades mediatizadas. Media \& Jornalismo, 11, 119-134. 


\section{NEW TECHNOLOGIES, RISKS AND OPPORTUNITIES FROM CHILDREN'S PERSPECTIVES}

\section{Abstract}

Assuming that children are active social agents who construct their own cultures, this research is focused on their perspective about the role that new technologies, particularly the Internet, have in their lives. Moreover, it aims to understand the opportunities, risks and safety challenges the use of digital technologies may represent, from the children's points of view. Based on an ethnographic approach, this article analyses children's lived experiences of using digital media, taking into account the specific sociocultural contexts in which these occur. Thus, it considers how technology and social practices coconstruct each other. Its results portray the 'digital' cultures children are building and the reinterpretations of opportunity, risk and safety that emerge within.

Keywords

Children; New technologies; Risks; Opportunities

\section{LAS NUEVAS TECNOLOGÍAS, SUS RIESGOS Y OPORTUNIDADES DESDE LA PERSPECTIVA DE LOS NIÑOS}

\section{Resumen}

Considerando que los niños son agentes sociales activos que construyen sus propias culturas, esta investigación buscó comprender sus puntos de vista acerca del papel que las nuevas tecnologías, en particular Internet, tienen en sus vidas. Aún tuvo como aspectos específicos los riegos, desafíos de seguridad y oportunidades que el uso de tecnologías digitales puede, o no puede, representar, desde el punto de vista de los niños. Con base en una investigación etnográfica están aquí representadas las culturas digitales que 
los niños están construyendo, bien como las interpretaciones que hacen de los conceptos de riesgo, seguridad y oportunidad. Este enfoque se centra en cómo se viven estas experiencias todos los días, en contextos de estructuras socio-culturales específicas. Se considera, por lo tanto, la dimensión social del fenómeno tecnológico, es decir, la manera como el desarrollo tecnológico y las prácticas sociales están interrelacionados y se construyen mutuamente.

Palabras-clave

Niños; Nuevas tecnologías; Riesgos; Oportunidades

Recebido em junho/2014

Aceite para publicação em abril/2015

i Centro de Investigação em Educação, Instituto de Educação, Universidade do Minho.

ii Centro de Investigação em Educação, Instituto de Educação, Universidade do Minho.

Toda a correspondência relativa a este artigo deve ser enviada para: Ana Francisca Monteiro, Centro de Investigação em Educação (CIEd), Campus de Gualtar, 4710 - 057 Braga, Portugal. E-mail: amonteiro@ie.uminho.pt 